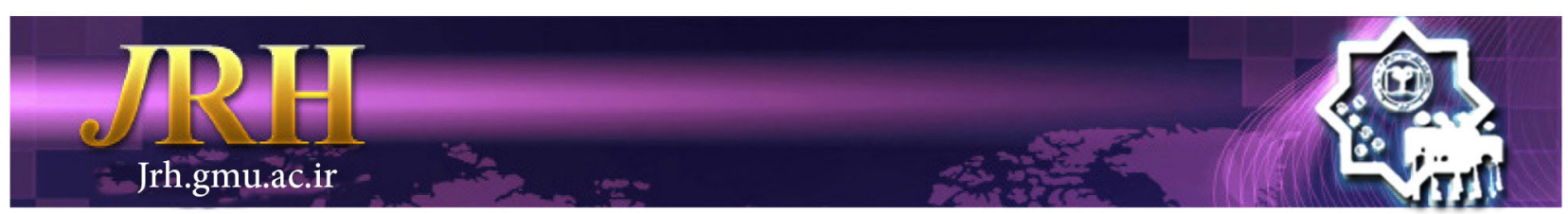

\title{
Group training based on acceptance-commitment approach for improving quality of life and reducing anxiety among diabetic women \\ Zahra Ghasemlou ${ }^{1}$, Atefe Nezhadmohammad Nameghi ${ }^{2}$
}

\author{
Journal of Research \& Health \\ Social Development \& Health Promotion \\ Research Center \\ Vol. 8, No.6, Nov \& Dec 2018 \\ Pages: 513- 521 \\ DOI: $10.29252 / j r h .8 .6 .513$ \\ Original Article
}

1. Department of Counseling, Faculty of Humanities and Social Sciences, Islamic Azad University, Research Branch of Tehran, Iran

2. Correspondence to: Department of Counseling, Faculty of Psychology, Islamic Azad University Branch of Karaj, Iran Email: nezhadmohamad@gmail.com

Received: 31 Oct 2017

Accepted: 12 Jun 2018

How to cite this article: Ghasemlou Z, Nezhadmohammad Nameghi A. Group training based on acceptance-commitment approach for improving quality of life and reducing anxiety among diabetic women. $J$ Research \& Health2018; 8(6): 513- 521.

\begin{abstract}
The Comorbidity of diabetes with psychological disorders negatively intensifies the symptoms of diabetic patients, reduces their response to treatment, decreases their life quality and consequently increases their mortality rate. The present study was conducted to investigate the effectiveness of group training based on acceptance and commitment in improving quality of life and reducing anxiety in diabetics. The present controlled experimental study was conducted using pretests and posttests. The statistical population comprised all women with diabetes presenting to a medical diagnostic laboratory in Shahriar, Iran. Convenience sampling was used to select highly anxious diabetics, who were assigned to experimental and control groups. The depression anxiety stress scale was used to measure anxiety and the SF-36 to assess quality of life in the samples. The 15-session protocol proposed by Eifert was also used for the group training of the concepts, principles and techniques of acceptance and commitment therapy (ACT). The results obtained suggested significant differences between the experimental and control groups in terms of anxiety and quality of life. In fact, acceptance and commitment based group training significantly reduced anxiety and improved quality of life in women with diabetes. Interventions for teaching the concepts, principles and techniques of ACT increased quality of life and reduced anxiety in women with diabetes. Teaching these concepts therefore can comprise a major mechanism for improving the process of healthy mental growth of women.
\end{abstract}

Keywords: Acceptance and Commitment Based, Anxiety, Diabetes, Quality of Life

\section{Introduction}

Chronic diseases constitute major health issues in modern communities and affect daily routine activities of the patients. Although conventional medical treatments alleviate the symptoms of chronic diseases, they themselves disrupt life pattern [1]. Diabetes is a common chronic, progressive and costly disease in Iran and across the world that causes numerous complications. This disease is a major health challenge that widely affects the patients' life and causes many illnesses including kidney, retina and heart problems [2]. The World Health Organization (WHO) estimated that the number of diabetics will increase from 171 million in 2000 to 366 million in 2030. Iranian people are also highly vulnerable to the risk of diabetes and recent studies suggest that $14-23 \%$ of Iranian adults over the age of 30 are diabetic or suffer from impaired glucose tolerance (IGT).

Diabetes often causes women more problems 
than men, which include increased vaginal fungal infections, vaginal dryness, decreased sexual desire and sexual dysfunction, in which Rina and colleagues have shown that diabetes is commonly affecting female sexual function [3]. Given the importance of sexual satisfaction, this factor can have a negative impact on women's quality of life [4]. In general, Camacho et al. [5] examined the quality of life of diabetic patients and concluded that increasing the severity of diabetes could have a significant negative effect on the quality of life of patients, especially in terms of psychological and social aspects.

Quality of life involves a sense of physical and psychological well-being, and refers to features by which individuals maintain their capabilities associated with valuable life activities. It also refers to emotional, social and physical health and improvement and the people's ability to perform daily activities [6]. The WHO defines quality of life as one's perception of their life status regarding the culture and value systems and their relationships with goals, expectations, interests, standards and life experiences. This concept comprises different dimensions and affects physical health, mental status, independence, social relationships and personal beliefs [5]. Camacho $\mathrm{F}$ et al. examined quality of life in diabetics and concluded that increasing the intensity of diabetes can cause many negative impacts, especially on the spiritual, psychological and social aspects of the patients' quality of life. As the goal of the social and economic policy, quality of life comprises all or a major part of life domains and its subcategories, improves one's material and immaterial conditions and involves group values, including freedom, justice and the guarantee of normal life conditions for the present and future generations [5].

Diabetes by itself causes significant mental pressure in the patients because they should deal with this disease for their whole life. In addition, humans often feel anxious and stressed in the face of threatening or stressful situations. This type of feelings is considered normal reactions to psychological pressure. Anxiety is abnormal only when it emerges in the face of easily- resolvable situations by most people. Sadeghi Movahhed, Molavi and Sharghi [6] found 54\% of the diabetics to have contracted suspected psychological disorders. With a prevalence of $41.7 \%$, anxiety disorders are common psychological disorders in diabetics [7].

Diabetes mellitus also has a lot of psychological pressure on people who suffer from diabetes, because they need to cope with this disease for life. On the other hand, people often feel anxiety and stress in facing threatening or stressful situations. Such feelings are normal responses to stress. Anxiety is only abnormal when it comes to situations where most people easily resolve them.

On the other hand, comorbidity of diabetes with symptoms and psychological disorders has a very negative effect on the exacerbation of symptoms, the occurrence of different side effects, reduced response to treatment and even increased mortality in diabetic patients. For example, we can point out the negative effect of mental disorders on blood glucose control [8]. Significant differences were also observed in anxiety symptoms between diabetics and healthy subjects [8]. Generalized anxiety disorder is the most prevalent type of anxiety disorder and is observed in $14 \%$ of the patients. Although the prevalence of anxiety symptoms is not different between patients with type 1 and 2 diabetes, it is higher in women than in men [9].

Normal anxiety is a common feeling that enhances performance and protection against dangers and makes up a major facilitator for passing evolutionary stages [10]. Abnormal anxiety is, however, an unpleasant emotion, some degree of which is experienced by all of us and is represented by terms such as "worry", "anxiety", "stress" and 'fear" [11]. Considering the discussed issues, the use of effective treatment in diabetic women to reduce symptoms of psychiatric disorders can have a positive effect on the lives of people with diabetes. On the other hand, various studies indicate the effectiveness of admission and commitment education [12-14]. Acceptance and Commitment 
Therapy (ACT) is the third wave evidencebased approach to the behavior theory and uses different methods to mix acceptance and awareness strategies with commitment and behavior change strategies, and emphasizes the change in the relationship of clients with internal experiences and avoidance [15]. ACT uses skills such as mindfulness, acceptance and cognitive diffusion to increase psychological flexibility [16], meaning experiencing and accepting psychological events, as they are, and being committed to fulfilling some jobs in the direction of individual values here and now. Many studies confirmed the effect of ACT on psychosomatic illnesses [14,17-19]. The goal of ACT is to change the relationship of clients with their thoughts and feelings, so that they are no longer considered symptoms; thereby causing abnormal damaging symptoms inhibiting a meaningful and enriched life to appear as a part of natural experiences of a meaningful life. Using methods such as ACT, with mindfulness as their main component, has been shown to affect the treatment of anxiety disorders [20]. Moreover, a case study suggested the effectiveness of ACT in alleviating depressive symptoms [12]. The participants who had simultaneously learned ACT and diabetes as well as subjects associated with education, acceptance, awareness about diabetes-associated thoughts and feelings, personal values related to diabetes and focus on abilities needed for a valuable movement throughout the experience of feelings were found to have a better blood glucose control compared to the participants who had only been trained on diabetes [13].

Considering the fact that research on the effect of acct on reducing anxiety and improving the quality of life of people with diabetes has not been found, according to the high rates of diabetes in Iran, the importance of quality of life in The ignorance can lead to hopelessness, mistrust, and diminished social, economic, cultural and health activities, and in a deeper way affect the socioeconomic development of the country. These questions arise as to whether acceptance and commitment-based treatment for improving the quality of life in patients Diabetes is effective. Does acceptance and commitment therapy affect the symptoms of anxiety symptoms in these people? In this research, we are looking to answer these questions.

\section{Method}

The design of the present study was a semiexperimental, pretest and posttest with control group. This design was chosen to reduce the risk of reputation. The statistical population of the present study consisted of all women with diabetes presenting to a specialist clinic in Shahriar, Iran from March to May 2016. Given the population type, convenience sampling was used to select 30 women with diabetes, who were randomly assigned to an experimental group $(n=12)$ and a control group $(n=13)$. The inclusion criteria comprised no history of hospitalization in the department of psychiatry and the associated medications, a minimum education level of high school diploma, not simultaneously participating in other educational treatment programs and being aged 20-45 years. After expressing the ethical issues that the researcher was required to observe (informed consent and privacy and privacy), the experimental group attended fifteen 90-minute ACT sessions. Before and after these 15 sessions, both groups completed the Depression Anexiety Stress Scale (DASS) and the Short Form Health Survey (SF-36).

DASS is a questionnaire for measuring anxiety and depression that has 21 items, This 21-item questionnaire measures negative emotions such as depression, anxiety and stress, and comprises three subscales, including depression, anxiety and stress, and every subscale contains seven items. The items are scored on a four-point Likert scale from zero (it does not apply to me at all) to three (it perfectly applies to me). The present study used only the anxiety subscale. Antoni et al conducted a factor analysis on this subscale and obtained three factors, including depression, anxiety and tension. The results of the study cited showed that $68 \%$ of the variance of the overall scale is measured by these three factors. The eigenvalue of anxiety 
in this study was equal to 1.23 and the alpha coefficient for the three factors was equal to 0.95 Asgharimoghadam MA, et al reported a Cronbach's alpha of 0.92 for the dimension of anxiety [21].

SF-36 In 2008, Ngo-Metzger Q presented a revised version of this tool containing 36 items and eight subscales. The present study used the overall score of this questionnaire ranging between zero and 100. Convergent validity was used to examine the validity of this questionnaire and all correlation coefficients obtained were above the recommended threshold of 0.04. Factor analysis also obtained two main components, which explained $65.9 \%$ of the dispersion among the questionnaire subscales. The reliability coefficient was found to be $0.77-0.95$ for eight dimensions except for the vitality, which was reported as 0.65 [22]. Group counseling based on Acceptance and Commitment Therapy (ACT) which has been developed based on Effort and Futures. The content of the educational sessions was as follows: Session 1: Orientation and introduction of the approach

Session 2: Identifying private experiences and thoughts from which the members avoided

Session 3: Focusing on the thoughts and feelings associated with diabetes rather than the disease itself

Session 4: Teaching creative methods of facing disappointment

Session 5: Teaching how to control or avoid difficult psychological problems

Session 6: Teaching fusion as well as clean and dirty discomfort

Session 7: Teaching defusion methods
Session 8: Teaching conceptualized selfalignment and how to defuse from it using metaphors and group exercises

Session 9: Teaching the mindfulness concepts and how to be present

Session 10: Session 9 continues

Session 11: Teaching and clarifying how to discriminate between goals and values

Session 12: Session 11 continues by performing exercises

Session 13: Focusing on values while emphasizing the dimensions of quality of life Session 14: Identifying and discussing barriers to value-based behaviors

Session 15: Evaluating, receiving feedback and concluding the sessions

The data obtained from completed questionnaires were analyzed in SPSS-20. Descriptive statistics were first used in this analysis. Kolmogorov-Smirnov test was used to investigate the normality of the data and the Levene's test to examine the homogeneity of intragroup variance.

\section{Results}

The descriptive and inferential findings of the present study obtained from the participants' statements indicated the effect of the concepts of ACT on treating parts of the problems of diabetics. Thirty women with diabetes participated in the present research. A maximum of $11(44 \%)$ of these women were aged $35-40$ and a minimum of $2(8 \%)$ were $40-$ 45. In terms of level of education, $16(64 \%)$ had high school diploma, $2(8 \%)$ associated diploma, 5 (20\%) bachelor's degree and 2 $(8 \%)$ Master of Science (MSc).

Table 1 The mean values of quality of life and anxiety in women with diabetes

\begin{tabular}{|c|c|c|c|c|c|c|c|}
\hline \multirow[b]{2}{*}{ Variable } & \multirow[b]{2}{*}{ Stage } & \multirow[b]{2}{*}{ Group } & \multirow[b]{2}{*}{ Frequency } & \multicolumn{2}{|c|}{ Pretest } & \multicolumn{2}{|c|}{ Posttest } \\
\hline & & & & Mean & $\begin{array}{c}\text { Standard } \\
\text { Deviation }\end{array}$ & Mean & $\begin{array}{c}\text { Standard } \\
\text { Deviation }\end{array}$ \\
\hline \multirow{2}{*}{ Quality of life } & \multirow{2}{*}{ Pretest } & Experimental & 12 & 94.166 & 5.39 & 106.75 & 5.18 \\
\hline & & Control & 13 & 93.92 & 10.94 & 99.00 & 8.86 \\
\hline \multirow{2}{*}{$\begin{array}{l}\text { Anxiety } \\
\text { symptoms }\end{array}$} & \multirow{2}{*}{ Pretest } & Experimental & 12 & 33.33 & 14.63 & 24.75 & 13.03 \\
\hline & & Control & 13 & 33.46 & 8.18 & 34.46 & 9.13 \\
\hline
\end{tabular}

According to Table 1, the mean posttest value of quality of life has increased in the experimental group compared to the pretest stage; this change was, however, insignificant in the controls.
Furthermore, the mean posttest value of anxiety has decreased in the experimental group, although the posttest increase observed in the controls is insignificant. 
Kolmogorov-Smirnov test was used to investigate the normality of the study variables' distribution. Given that the significance level was higher than the critical value of 0.05 for both 'quality of life' and 'anxiety' in the pretest and posttest, the data of both variables are concluded to follow a normal distribution.

Table 2 The Kolmogorov-Smirnov test for examining normality

\begin{tabular}{lccc}
\hline Variable & Statistic & Pretest & Posttest \\
\hline \multirow{2}{*}{ Quality of life } & Kolmogorov-Smirnov & 0.160 & 0.139 \\
& Level of significance & 0.098 & 0.200 \\
\hline \multirow{2}{*}{ Anxiety } & Kolmogorov-Smirnov & 0.172 & 0.100 \\
& Level of significance & 0.056 & 0.200 \\
\hline
\end{tabular}

The results of the Levene's test used to group variance is homogeneous for both investigate this hypothesis showed that the variables of quality of life and anxiety.

Table 3 Homogeneity of variance

\begin{tabular}{lccccc}
\hline \multirow{2}{*}{ Quality of life } & Levene's test & $\begin{array}{r}\text { Degree of } \\
\text { freedom 1 }\end{array}$ & $\begin{array}{r}\text { Degree of } \\
\text { freedom 2 }\end{array}$ & Significance level \\
\hline \multirow{2}{*}{ Anxiety } & Posttest & 1.656 & 1 & 23 & 0.211 \\
& Pretest & 3.234 & 1 & 23 & 0.278 \\
\hline
\end{tabular}

For quality of life, the F value of the independent variable interaction and variance equals 3.470, which is insignificant. For anxiety, the F value of the independent variable interaction and variance is 2.194, which is insignificant. The hypothesis of the homogeneity of the regression slope is therefore satisfied for both variables.

Table 4 The ANCOVA of educational interventions based on acceptance and commitment in women's quality of life

\begin{tabular}{lcccccc}
\hline Quality of life & Sum of squares & $\begin{array}{c}\text { Degree of } \\
\text { freedom }\end{array}$ & $\begin{array}{c}\text { Mean } \\
\text { square }\end{array}$ & F & $\begin{array}{c}\text { Significance } \\
\text { level }\end{array}$ & Eta squared \\
\hline Cumulative model & 330.589 & 2 & 165.295 & 3.543 & 0.046 & 0.244 \\
Interactive & 2663.204 & 1 & 2553.204 & 57.085 & $<0.001$ & 0.721 \\
Pretest & 5.202 & 1 & 5.202 & 0.111 & 0.742 & 0.181 \\
Group & 226.546 & 1 & 226.546 & 4.856 & 0.038 & 0.51 \\
Error & 1026.371 & 22 & 46.653 & & & \\
Overall & 256180.000 & 25 & & & & \\
\hline
\end{tabular}

Table 4 suggested significant differences between women with diabetes in the experimental and control group in terms of quality of life $(p<0.05)$. In other words, ACT increased quality of life in women with diabetes. The eta coefficient also shows that mindfulness-based education explains 51\% of the variance of quality of life.

Table 5 The ANCOVA of the effect of ACT-based educational intervention on women's anxiety

\begin{tabular}{lcccccc}
\hline Anxiety symptoms & $\begin{array}{c}\text { Sum of } \\
\text { squares }\end{array}$ & $\begin{array}{c}\text { Degree of } \\
\text { freedom }\end{array}$ & $\begin{array}{c}\text { Mean } \\
\text { square }\end{array}$ & F & $\begin{array}{c}\text { Significance } \\
\text { level }\end{array}$ & Eta squared \\
\hline Cumulative model & 588.690 & 2 & 294.345 & 2.257 & 0.128 & 0.170 \\
Interactive & 2134.800 & 1 & 2134.800 & 16.368 & 0.001 & 0.427 \\
Pretest & 332.171 & 1 & 332.171 & 2.545 & 0.051 & 0.110 \\
Group & 586.041 & 1 & 586.041 & 4.493 & 0.046 & 0.170 \\
Error & 2869.310 & 22 & 130.4930 & & & \\
Overall & 25659.00 & 25 & & & & \\
\hline
\end{tabular}


Table 5 suggested significant differences between the women with type 2 diabetes in the experimental and control group in terms of anxiety $(p<0.05)$, meaning ACT reduced anxiety in the female patients. The eta coefficient also shows that mindfulness-based education explains $17 \%$ of the variance of anxiety in the women with diabetes.

\section{Discussion}

The results showed significant differences between the women in the experimental group and those in the control group in terms of the scores of quality of life (Table 4) and anxiety (Table 5). In other words, education based on acceptance and commitment improved quality of life and reduced anxiety in women with diabetes. The findings of this study are consistent with other research findings that examine the effect of learningbased commitment and admission on the psychological components of patients suffering from chronic physical illnesses such as cancer and diabetes [17,23-35].

Physiological stress causes many health problems. Due to the stress caused by being forced to follow certain diets and the awareness about diabetes complications, diabetics resort to negative methods and deny their disease and associate their physical symptoms to other treatable gastrointestinal and renal diseases [14]. The principle behind the acceptance and commitment based approach is that accepting the suffering by the patient is the most important step towards redemption. Teaching methods of tolerating this suffering and exercising and applying them in sessions and at home provide women with the opportunity to change themselves. Moreover, women can actively and consciously learn to better accept unpleasant life experiences without attempting to avoid inevitable life situations or trying to endure undesirable conditions. They can also learn how to actively and enthusiastically deal with their emotions, memories and physical sensations. Increasing the acceptance level and reducing intellectual inhibition have therefore decreased the stress which causes physiological stress and physical pain and discomfort.

Quality of life confirms one's perception of their effective physical, psychological and social performance. Focusing patients' attention and consciousness on life values and identifying actual values of life cause the emergence of committed activities and behaviors in line with those values. Emotional reactions to life events, attitudes, feeling perfect in life and being satisfied with it, job satisfaction and interpersonal relationships have been shown to improve quality of life and reduce anxiety. Given that diabetics suffer from negative emotions, numerous inefficient thoughts and efforts for avoiding these thoughts and emotions, ACT, increased cognitive defusion and informed acceptance help the participants experience new methods in their relationships and interactions with negative thoughts. Creating and reinforcing acceptance in clients reduce cognitive avoidance and supports a valuebased life style and also improves the performance of women with diabetes in different domains of life.

Diabetics found the opportunity to achieve psychological flexibility by giving up experimental avoidance, meaning the patient's attempt for controlling, replacing or escaping internal events, and using creative disappointment and confronting and accepting the situations and thoughts that they previously avoided and clarifying communication values and being committed to consistent action. Psychological flexibility refers to the ability to contact the present time and psychological reactions that make the patients aware and change their behaviors or stabilize them in line with their selected values. This acceptance and improved flexibility have also enhanced the patients' quality of life.

According to the acceptance and commitment pathology model, patients with psychological problems face cognitive fusion, which causes them to react against their thoughts in two ways; they may adjust and guide their 
behavior as per their thoughts or they may fight with and avoid their thoughts. Teaching how to constantly use experimental avoidance helps the patients resolve their unpleasant feelings. In the long run, avoidance turns into a coping strategy and helps the patients try to nullify or avoid their unpleasant feelings rather than striving for their life values [36]. By identifying and neutralizing avoidance and using the creative disappointment technique, metaphors and allegories, ACT introduces acceptance to the patient as an important alternative to experimental avoidance. Accepting the disease and its complications can reduce anxiety. These complications naturally involve physical and psychological pains as a major cause of anxiety. Acceptance in this approach involves the active and informed acceptance of personal events, which are associated with both the patient's biography and the lack of attempts for reducing the frequency and changing the form of those events, especially when they cause psychological damage. The patients are then taught to reduce cognitive fusion as a major cause of anxiety and establish more effective relationships with their internal events by not taking them seriously. Helping the women identify their personal values to which they had been inattentive so far and teaching the activities necessary for achieving these values ultimately reduced their anxiety.

Higher levels of teaching skill and preparedness are recommended to be used in future studies. Males are also recommended to be taught and compared with females. The subjects' blood glucose is recommended to be measured after the trainings to help determine the effect of educational interventions on the improvement of the disease.

Since this therapeutic approach, as its shortterm relevance, has a positive impact on the quality of life of people with diabetes, healthcare providers, along with medical services that give diabetics, do not leave them with effective psychological services, and can hold acceptance and commitment therapy courses at health centers for them.
The present study faced limitations like other studies. Limiting the samples to women and the lack of participation of men was a limitation. The limited sample size $(n=15)$ was another limitation which may restrict the generalizability of the results. The self-report nature of the tool and the potential awareness of the subjects about the test was also a limitation, which should be taken care of. Although the researchers were skilled, they faced problems with teaching the concepts, principles and techniques of the acceptance and commitment approach, which affected their quality of teaching. In addition, the subjects' blood glucose was not measured after the training programs.

\section{Conclusion}

ACT helped women with type 2 diabetes reduce their anxiety associated with the disease and daily events and improve their quality of life through laying the groundwork for accepting emotions, teaching the patients how to get rid of useless fights and attempts for using other control methods and eliminating negative emotions and experiences and ultimately by encouraging them to follow their values and consequently become committed to acting based on values.

\section{Acknowledgements}

The present research was extracted from a Master's thesis written by the corresponding author in collaboration with the medical diagnostic laboratory of the city of Shahriar. The authors would like to express their gratitude to all the authorities and staff of the medical diagnostic laboratory of Shahriar and the supervisor, who helped conduct this study.

\section{Contribution}

Study design: AN, ZGH

Data collection and analysis: $\mathrm{ZGH}$

Manuscript preparation: ZGH

\section{Conflicts of Interest}

"The authors declare that they have no 
competing interests".

\section{Funding}

The author (s) received no financial support for the research, authorship and/or publication of this article.

\section{References}

1-Fitzgerald Miller J. Coping with chronic illness: overcoming powerlessness. Philadelphia, PA: F.A. Davis; 1999.

2- Musazadeh T, Adib A, Motavally R. A comparative study of level and way of using defense mechanisms by diabetic and healthy individuals in 2007. Medical Sciences Journal of Islamic Azad University, Tehran Medical Branch2009; 19(1): 61-4.

3- Donald A.What is quality of life? Sponsored by an educational grant from Aventis Pharma. 2001. Available at URL: www.bandolier.org.uk/painres/download/ whatis\%20copy/WhatisQOL.pdf. Accessed July 2016.

4- Zaeri S, Asgharzadeh S, Zaeri M, Holakouie Naeini K, Rahimi Foroushani A. The Quality of Life and Its Effective Factors in the Eldery living Population of Azerbaijan District, Tehran, Iran. Iranian Journal of Epidemology2014;9(4): 66-74.

5- Biswas- Diener R, Diener E. Making. the best of a bad situation: satisfaction in the slums of Calcutta. Soc Indic Res2001; 55(3): 329-52.

6- Sadeghi Movahhed F, Molavi P, Sharghi A, et al. On the relationship between coping strategies and mental health of diabetic patients. Journal of Fundamentals of Mental Health2010; 12(2): 480-7.

7- Zhang CX, Chen YM, Chen WQ. Association of psychosocial factors with anxiety and depressive symptoms in Chinese patients with type 2 diabetes. Diabetes Res Clin Pract2008; 79(3): 523-30.

9- Grigsby AB, Anderson RJ, Freedland KE, Clouse RE, Lustman PJ. Prevalence of anxiety in adults with diabetes: a systematic review. J Psychosom Res2002; 53(6): 1053-60. 10- Vasa RA, Pine DS. Anxiety disorders. In: Essau C, ed. Child and adolescent psychopathology: theoretical and clinical implications. New York, NY, US: Routledge/ Taylor \& Francis Group; 2006. pp: 78-112.

11- Atkinson R, Atkinson RC, Smith EA, Bem DJ, NolenKoeksema S. Hilgard's introduction to psychology. Translation by Brahnei M, Birashk B, Beik M, et al. Tehran: Roshd publishing; 2005.

12- Kanter JW, Baruch DE, Gaynor ST. Acceptance and commitment therapy and behavioral activation for the treatment of depression: description and comparison. Behav Anal2006; 29(2): 161-85.

13-Gregg JA, Callaghan GM, Hayes SC, Glenn-Lawson JL. Improving diabetes self-management through acceptance, mindfulness, and values: a randomized controlled trial. $J$ Consult Clin Psychol2007; 75(2): 336-43.

14- Kahl KG, Winter L, Schweiger U. The third wave of cognitive behavioural therapies: what is new and what is effective? Curr Opin Psychiatr2012; 25(6): 522-8.

15- Roemer L, Orsillo SM. An acceptance-based behavior therapy for generalized anxiety disorder. In: Orsillo SM, Roemer L, eds. Acceptance- and mindfulness-based approaches to anxiety. New York, NY: Springer; 2010. pp: 213-40.

16- Forman EM, Herbert JD. New directions in cognitive behavior therapy: acceptance-based therapies. In: O'Donohue WT, Fisher JE, eds. General principles and empirically supported techniques of cognitive behavior therapy. 2nd ed. Hoboken, NJ: John Wiley \& Sons, Inc; 2008. pp: 77-94.

17- Rajabi S, Yazdkhasti F. The effectiveness of acceptance and commitment group therapy on anxiety and depression in women with MS who were referred to the MS association. Journal of Clinical Psycology2014: 1(21): 29-38

18- Dionne F, Blais MC, Monestès JL. Acceptance and commitment therapy in the treatment of chronic pain. Sante Ment Que2013; 38(2): 131-52.

19- Dionne F, Ngô TL, Blais MC. The psychological flexibility model: a new approach to mental health. Sante Ment Que2013; 38(2): 111-30.

20- Block JA, Wulfert E. Acceptance or change: Treating socially anxious college students with ACT or CBGT. Behav Anal Today2000; 1(2): 3-10.

21- Asghari Moghadam MA, Saed F, Dibaj Nia P, Zanganeh J. A preliminary study on the validity and reliability of the Depression, anxiety and stress in nonclinical samples (DASS). Scientific-Research Journal of Shahed University (Daneshvar)2008; 15(31): 23-38.

22- Montazeri A, Ghatbasbi A, Vohadani Nia MS. Translation, reliability and validation of Persian type SF-36 standard. Journal of the Iranian Institute for Health Sciences Research (Payesh)2006: 5(1). 49-56. 23- Mohabat Bahar S, Akbari ME, Maleki F, MoradiJoo M. The effectiveness of group psychotherapy based on acceptance and commitment on quality of life in women with breast cancer. Journal of Clinical Psychology Andishe va Raftar2015: 9(34): 17- 26.

24- Gharaei Ardakani SH, Azadfallah P, Tavallaei A. The effectiveness of acceptance and commitment therapy on pain experience in women with chronic pain. Journal of Clinical Psychology2012; 4(14): 39-50.

25- Anvari MH, Ebrahimi A, Taher Neshatdoost H, Afshar H, Abedi A. The effectiveness of group-based acceptance and commitment therapy on pain-related anxiety, acceptance of pain and pain intensity in patients with chronic pain. Journal of Isfahan Medical School2014; 32(295): 1-10. 
26- Twohig MP. The application of acceptance and commitment therapy to obsessive-compulsive disorder. Cogn Behav Pract2008; 16(1): 18-28.

27- López FJC, Valdivia-Salas S. Acceptance and commitment therapy (ACT) in the treatment of panic disorder: some considerations from the research on basic processes. Rev Int Psicol Ter Psicol2009; 9(3): 299-315 28- Lundgren T, Dahl J, Yardi N, Melin L. Acceptance and commitment therapy and yoga for drug-refractory epilepsy: a randomized controlled trial. Epilepsy Behav2008; 13(1): 102-8.

29- Pourfaraj Omran M. The effectiveness of acceptance and commitment group therapy in social phobia of students. Knowledge Health2011; 6(2). 1-5.

30- Ossman WA, Wilson KG, Storaasli RD. McNeill JW. A preliminary investigation of the use of acceptance and commitment therapy in group treatment for social phobia. Rev Int Psicol Ter Psicol2006; 6(3): 397-416.

31- Zettle RD. Acceptance and commitment therapy mathematics anxiety. Psychol Rec2003; 53(2): 197-215. 32- Izadi R, Abedi MR. Alleviation of obsessive symptoms in treatment-resistant obsessive-compulsive disorder using acceptance and commitment-based therapy. Feyz Journal of Kashan University of Medical Sciences2013; 17(3): 275-86.

33- Twohig MP, Hayes SC, Masuda A. A preliminary investigation of acceptance and commitment therapy as a treatment for chronic skin picking. Behav Res Ther2006; 44(10): 1513-22.

34-Aarab Shaibani Kh. The effectiveness of intervention based on acceptance and commitment on emotions and thoughts control in patients with type II diabetes. Fundamentals of Mental Health2017; 19(4): 341-7.

35- Felce D, Perry J. Quality of life: its definition and measurement. Res Dev Disabil1995; 16(1): 51-74.

36-Herbert JD, Forman EM.Acceptance and mindfulness in cognitive behavior therapy: understanding and applying the new therapies. Hoboken, NJ: John Wiley \& Sons, Inc; 2011.

(Act) vs. Systematic Desensitization in Treatment of

Copyright(C) 2016 ASP Ins. This open-access article is published under the terms of the Creative Commons Attribution-NonCommercial 4.0 International License which permits Share (copy and redistribute the material in any medium or format) and Adapt (remix, transform, and build upon the material) under the Attribution-NonCommercial terms. 